\title{
Conformational cooling and conformation selective aggregation in dimethyl sulfite isolated in solid rare gases
}

\author{
Ana Borba ${ }^{a}$, Andrea Gómez-Zavaglia ${ }^{\text {a,b }}$, Rui Fausto ${ }^{\mathrm{a}, *}$ \\ a Department of Chemistry, University of Coimbra, Rua Larga, P-3004-535 Coimbra, Portugal \\ ${ }^{\mathrm{b}}$ Facultad de Farmacia y Bioquímica, Universidad de Buenos Aires, Buenos Aires, RA-1113, Argentina \\ Received 30 January 2006; received in revised form 6 February 2006; accepted 6 February 2006 \\ Available online 27 March 2006
}

\begin{abstract}
Dimethyl sulfite has three conformers of low energy, GG, GT and $\mathrm{GG}^{\prime}$, which have significant populations in the gas phase at room temperature. According to theoretical predictions, the GT and $\mathrm{GG}^{\prime}$ conformers are higher in energy than the GG conformer by 0.83 and $1.18 \mathrm{~kJ} \mathrm{~mol}^{-1}$, respectively, while the barriers associated with the $\mathrm{GG}^{\prime} \rightarrow \mathrm{GT}$ and $\mathrm{GT} \rightarrow \mathrm{GG}$ isomerizations are 1.90 and $9.64 \mathrm{~kJ}^{\mathrm{mol}}{ }^{-1}$, respectively. Experimental data obtained for the compound isolated in solid argon, krypton and xenon demonstrated that the GG $\rightarrow \mathrm{GT}^{\prime}$ energy barrier is low enough to allow an extensive conversion of the $\mathrm{GG}^{\prime}$ form into the GT conformer during deposition of the matrices, the extent of the conversion increasing along the series $\mathrm{Ar}<\mathrm{Kr}<\mathrm{Xe}$. Indeed, for substrate temperatures lower than ca. $30 \mathrm{~K}$, the three conformers could be trapped in both argon and krypton matrices, but, at a given temperature, the amount of $\mathrm{GG}^{\prime}$ form trapped in krypton is considerably smaller than in argon, while the amount of GT form increases in relation to the most stable GG form. In addition, when xenon is used, no bands due to GG ${ }^{\prime}$ are observed in the as-deposited spectra $\left(T_{\text {substrate }} \geq 10 \mathrm{~K}\right.$, the minimum substrate temperature accessible to our experimental set up), indicating that when the best relaxant gas is used the $\mathrm{GG}^{\prime} \rightarrow \mathrm{GT}$ conversion during deposition of the matrix is complete even at $10 \mathrm{~K}$. Annealing of the argon and krypton matrices shows that the increase of the temperature of the matrix first promotes the $\mathrm{GG}^{\prime} \rightarrow \mathrm{GT}$ isomerization, and only at higher temperatures the $\mathrm{GT} \rightarrow \mathrm{GG}$ conversion starts to occur, in consonance with the relative energy barriers associated with these two processes. The results also indicate that dimethyl sulfite exhibits conformation selective aggregation, with the most stable form, which has the highest dipole moment, aggregating more easily than the remaining experimentally relevant conformers (GT and GG').
\end{abstract}

(C) 2006 Elsevier B.V. All rights reserved.

Keywords: Matrix isolation FTIR Spectroscopy; Dimethyl sulfite; Conformational cooling; Conformation selective aggregation

\section{Introduction}

Dimethyl sulfite $\left(\mathrm{DMSO}_{3}\right)$ is the simplest member of the organic sulfites' family and has been shown to have many important biological applications (e.g. as insect repellent and odorant), being present, for instance, in male preputial glands $[1,2]$. Due to its reactivity towards different nucleofiles, $\mathrm{DMSO}_{3}$ has also been currently used in organic synthesis [3].

The study of the vibrational spectra of the compound in different experimental conditions has been carried out by different authors [4-10]. Klaeboe [7] was the first to undertake a tentative assignment of the fundamental vibrations of liquid $\mathrm{DMSO}_{3}$ (at room temperature) by infrared and Raman

\footnotetext{
* Corresponding author. Tel.: +351239 852080; fax: +351239827703.

E-mail address: rfausto@ci.uc.pt (R. Fausto).
}

0022-2860/\$ - see front matter (C) 2006 Elsevier B.V. All rights reserved. doi:10.1016/j.molstruc.2006.02.005 spectroscopies. In spite of the fact that Klaeboe has not explicitly considered conformational rotamerism, this possibility was not excluded. In a more recent study of $\mathrm{DMSO}_{3}$, Odeurs et al. [8] have investigated the gas phase conformational preferences of this molecule, based on the analysis of the observed $\nu \mathrm{S}=\mathrm{O}$ infrared band profile. According to that work, two conformers (forms GG and GT, shown in Fig. 1), should constitute the vast majority of the species present in the conformational equilibrium in the gaseous phase. In 1987, Barnes and Van der Veken [9] were able to isolate $\mathrm{DMSO}_{3}$ and its perdeuterated derivative in argon and nitrogen matrices at $20 \mathrm{~K}$. This was the first work to report the co-existence of three conformers of $\mathrm{DMSO}_{3}$. The annealing of the matrices up to ca. $30 \mathrm{~K}$ induced the disappearance of the bands corresponding to the less stable conformers, thus giving clear evidence that the relevant barriers for conformational isomerization should be smaller than ca. $8 \mathrm{~kJ} \mathrm{~mol}^{-1}[9,11]$. In spite of the fact that the powerful methods of calculation used routinely nowadays to support the assignment of vibrational spectra were not 

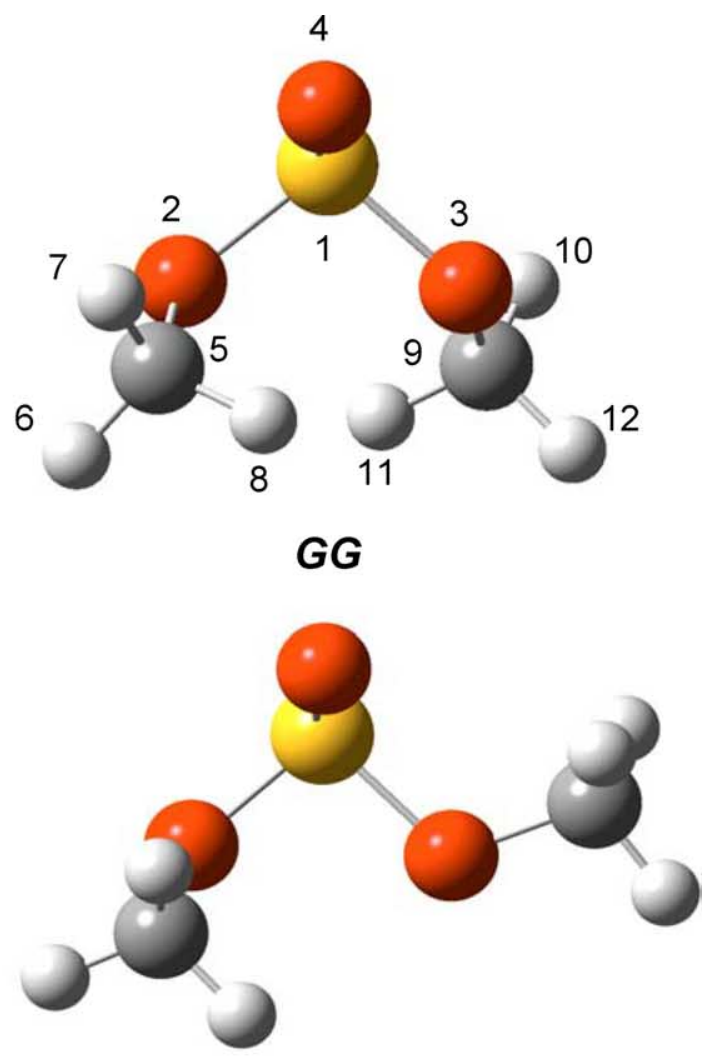

GT

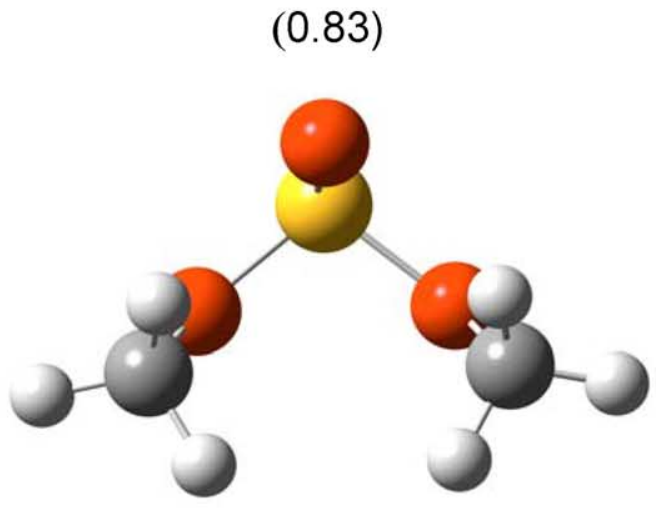

GG'

$(1.18)$

Fig. 1. Experimentally relevant conformers of $\mathrm{DMSO}_{3}$ optimized at the DFT/aug-cc-pVDZ level of calculation with atom numbering scheme. Relative energies $\left(\mathrm{kJ} \mathrm{mol}^{-1}\right)$ to the most stable conformer $(\mathrm{GG})$ are shown in parentheses. The calculated $\mathrm{O} 4=\mathrm{S} 1-\mathrm{O} 2-\mathrm{C} 5$ and $\mathrm{O} 4=\mathrm{S} 1-\mathrm{O} 3-\mathrm{C} 9$ dihedral angles, which define the conformation, are $73.2^{\circ} / 70.8^{\circ}, 68.5^{\circ}-173.2^{\circ}$ and $85.7^{\circ} \%-85.7^{\circ}$, respectively.

available at that time, Barnes and Van der Veken were able to present a first assignment of the bands corresponding to each conformer taking advantage of isotopic labeling and carefully executed annealing experiments in both argon and nitrogen matrices. In consonance with the results of Barnes and Van der Veken [9], we have recently proved the presence of three conformers (GG, GT and $\mathrm{GG}^{\prime}$; Fig. 1) of $\mathrm{DMSO}_{3}$ in argon matrices [10]. In our previous study, we have also reported results of high-level theoretical calculations on the studied compound, using the extended quadruple- $\zeta$ aug-cc-pQVZ basis set, together with the DFT/B3LYP method. The calculated energies for the GT and $\mathrm{GG}^{\prime}$ conformers were predicted to be 0.83 and $1.18 \mathrm{~kJ} \mathrm{~mol}^{-1}$, respectively, above that of the most stable GG conformer [10]. The energy barriers associated with the $\mathrm{GG}^{\prime} \rightarrow \mathrm{GT}$ and $\mathrm{GT} \rightarrow \mathrm{GG}$ isomerization processes were also estimated theoretically. The first was predicted to be very small $\left(1.90 \mathrm{~kJ} \mathrm{~mol}^{-1}\right)$, while the second was found to be somewhat higher, $9.64 \mathrm{~kJ} \mathrm{~mol}^{-1}$, but still low enough to eventually allow for the isomerization process to be observed during matrix deposition or by annealing of the matrix after deposition. On the other hand, the $\mathrm{GG}^{\prime} \rightarrow \mathrm{GG}$ process has been found to have a considerably higher energy barrier $\left(19.5 \mathrm{~kJ} \mathrm{~mol}^{-1}\right)$ [10].

Conformational cooling (change of population towards lower energy conformational levels, but without requiring the existence of a thermodynamic temperature) has been observed to take place during matrix deposition for other compounds having different conformational states of similar energies separated by low energy barriers, such as cyanoacetic acid, methyl cyanoacetate, glycine and dimethylglycine methyl ester [12-18], for example. The observation of only two conformers $\left(\mathrm{GT}\right.$ and $\mathrm{GG}^{\prime}$ ) of $\mathrm{DMSO}_{3}$ isolated in solid xenon [10] was a clear indication that this effect does also take place in the case of this compound. In our previous study on $\mathrm{DMSO}_{3}$ [10], this topic was addressed briefly. In the present paper, it is investigated in detail. To fulfill this aim, $\mathrm{DMSO}_{3}$ was isolated using matrix gases with known different relaxant capabilities (argon $<$ krypton $<$ xenon [13]) and a wide range of deposition temperatures.

The use of the higher temperature matrices (in particular, xenon matrices) also enabled us to investigate the aggregation process in $\mathrm{DMSO}_{3}$. As it will be shown below, the most stable conformer of $\mathrm{DMSO}_{3}(\mathrm{GG})$ seems to have a trend to aggregate easier than the higher energy GT and $\mathrm{GG}^{\prime}$ forms.

\section{Materials and methods}

Dimethyl sulfite was obtained from Aldrich (purity 99\%). The IR spectra were collected, with $0.5 \mathrm{~cm}^{-1}$ spectral resolution, on a Mattson (Infinity 60AR Series) fourier transform infrared spectrometer, equipped with a deuterated triglycine sulfate (DTGS) detector and a Ge/KBr beamsplitter. Necessary modifications of the sample compartment of the spectrometer were made in order to accommodate the cryostat head and allow efficient purging of the instrument by a stream of dry $\mathrm{N}_{2}$ to remove water and $\mathrm{CO}_{2}$ vapors.

In the matrix isolation experiments, a glass vacuum system and standard manometric procedures were used to deposit the matrix gas (argon N60, krypton N48 or xenon N48, all of them obtained from Air Liquide). Matrices were prepared by co-deposition, onto the cooled CsI substrate of the cryostat, of the matrix gas and $\mathrm{DMSO}_{3}$, which was sublimated using a specially designed doubly thermostable Knudsen cell with shut-off possibility. The container of the Knudsen cell was kept at low temperature $\left(\mathrm{ca} .-100{ }^{\circ} \mathrm{C}\right.$ ) to reduce the vapor pressure of the compound and enable a better control of the amount of 
$\mathrm{DMSO}_{3}$ being deposited, while the nozzle was kept at room temperature $(298 \mathrm{~K})$. All experiments were done on the basis of an APD Cryogenics close-cycle helium refrigeration system with a DE-202A expander. Different deposition temperatures were used, ranging from 10 to $30 \mathrm{~K}$ ( $\mathrm{Ar}$ and $\mathrm{Kr}$ ) or 10 to $50 \mathrm{~K}$ (Xe). After depositing of the compound, annealing experiments were performed until a temperature of $35 \mathrm{~K}(\mathrm{Ar}), 55 \mathrm{~K}(\mathrm{Kr})$ or $60 \mathrm{~K}(\mathrm{Xe})$ was attained.

\section{Results and discussion}

The as-deposited spectra of $\mathrm{DMSO}_{3}$ in argon, krypton and xenon matrices, using a substrate temperature of $10 \mathrm{~K}$ (with the valve nozzle at room temperature, $298 \mathrm{~K}$ ), are displayed in Fig. 2. The DFT (B3LYP)/aug-cc-pVQZ calculated spectra [10] for the three experimentally relevant conformers of $\mathrm{DMSO}_{3}\left(\mathrm{GG}, \mathrm{GT}\right.$ and $\left.\mathrm{GG}^{\prime}\right)$ are also shown in this figure for comparison. Tables 1-3 show the assignments made for the spectra collected in the three types of matrices. As it was mentioned in our previous work [10], the matrix isolation spectra of $\mathrm{DMSO}_{3}$, as found for other analogous sulfur containing compounds [19], exhibit band-splitting (which in $\mathrm{DMSO}_{3}$ becomes more evident for the features assigned to the GT and $\mathrm{GG}^{\prime}$ forms) due to occupancy of different matrix-sites. This effect is more pronounced in argon and krypton matrices, but it also exists in xenon. Some of the bands originated in different matrix-sites displayed intensity reorganization when the compound was deposited at different temperatures of the substrate, indicating that the stability of the different matrixsites shall be at least slightly different.
As shown in Fig. 2, using $T_{\text {substrate }}=10 \mathrm{~K}$ the GG, GT and $\mathrm{GG}^{\prime}$ conformers could be trapped in argon and krypton matrices, but not in xenon, where no bands of $\mathrm{GG}^{\prime}$ were observed (this may be particularly well seen in the $\nu \mathrm{S}=\mathrm{O}$ stretching region-Fig. 2a, where the bands due to the different conformers appear well separated, but is also consistently observed along the spectra-see, for example, the 1020-950 and $760-650 \mathrm{~cm}^{-1}$ regions shown in Fig. $2 b$ and c). As mentioned before, this fact indicates the occurrence of extensive conformational cooling during deposition of the xenon matrix, due to isomerization of conformer $\mathrm{GG}^{\prime}$ into form GT. Accordingly to this interpretation, the relative intensity of the bands corresponding to GT in the Xe matrix should be nearly equal to the sum of the relative intensities of the bands of $\mathrm{GT}$ and $\mathrm{GG}^{\prime}$ in the other two matrices. On the other hand, the relative intensity of the bands due to conformer GG should be nearly equal in the three matrices, since no isomerization from GT and $\mathrm{GG}^{\prime}$ into $\mathrm{GG}$ is expected to take place at this low temperature of deposition due to the higher energy barriers associated with both the GT $\rightarrow \mathrm{GG}$ and $\mathrm{GG}^{\prime} \rightarrow \mathrm{GG}$ processes (9.4 and $19.5 \mathrm{~kJ} \mathrm{~mol}^{-1}$, respectively).

The relative populations of the three $\mathrm{DMSO}_{3}$ conformers in the three studied matrices deposited at $10 \mathrm{~K}$ are presented in the graphic shown in Fig. 3. The populations were estimated from the integral intensity of the bands in the $1250-1180 \mathrm{~cm}^{-1}$ spectral region $(\nu \mathrm{S}=\mathrm{O})$, weighted by the corresponding calculated [DFT(B3LYP)/aug-cc-pVQZ] intensities. In consonance with the expectations, the population of the GG form trapped in $\mathrm{Ar}$ and $\mathrm{Kr}$ matrices and the sum of the populations of GT and $\mathrm{GG}^{\prime}$ forms are approximately the same.
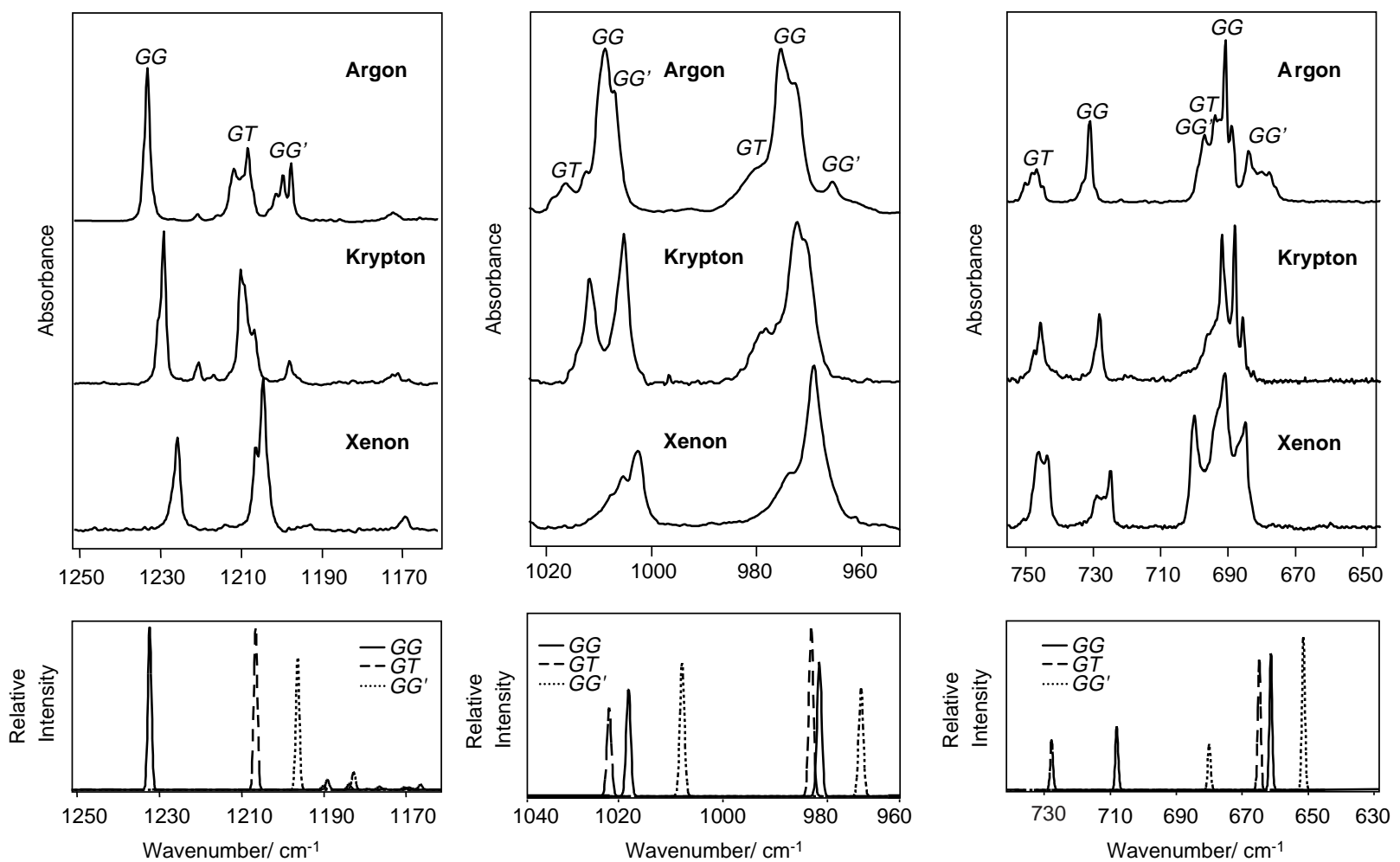

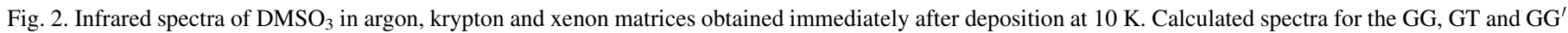
conformers are also displayed for comparison: (a) $1240-1185 \mathrm{~cm}^{-1}$ region; (b) $1020-960 \mathrm{~cm}^{-1}$ region; (c) $755-660 \mathrm{~cm}{ }^{-1}$ region. 
Table 1

Observed frequencies $\left(\mathrm{cm}^{-1}\right)$ for the GG form of dimethyl sulfite monomer in argon, krypton and xenon matrices

\begin{tabular}{|c|c|c|c|c|c|c|c|c|}
\hline \multirow{2}{*}{$\begin{array}{l}\text { Approximate } \\
\text { description }\end{array}$} & \multirow{2}{*}{$\begin{array}{l}\text { Calculated fre- } \\
\text { quency }\end{array}$} & \multirow{2}{*}{$\begin{array}{l}\text { Calculated } \\
\text { intensity }\end{array}$} & \multicolumn{2}{|c|}{ Observed frequency $\operatorname{Ar}(10 \mathrm{~K})$} & \multicolumn{2}{|c|}{ Observed frequency $\mathrm{Kr}(10 \mathrm{~K})$} & \multicolumn{2}{|c|}{ Observed frequency (10 K) } \\
\hline & & & $\begin{array}{l}\text { More stable } \\
\text { site }\end{array}$ & $\begin{array}{l}\text { Less stable } \\
\text { sites }\end{array}$ & $\begin{array}{l}\text { More stable } \\
\text { site }\end{array}$ & $\begin{array}{l}\text { Less stable } \\
\text { sites }\end{array}$ & $\begin{array}{l}\text { More stable } \\
\text { sites }\end{array}$ & $\begin{array}{l}\text { Less stable } \\
\text { sites }\end{array}$ \\
\hline$\nu\left(\mathrm{C} 9-\mathrm{H}_{3}\right)^{\prime}$ as & 3147.2 & 6.1 & \multicolumn{2}{|l|}{3028.0} & \multicolumn{2}{|l|}{3017.0} & \multicolumn{2}{|l|}{3022.3} \\
\hline$\nu\left(\mathrm{C} 5-\mathrm{H}_{3}\right)^{\prime}$ as & 3133.7 & 9.4 & \multicolumn{2}{|l|}{3028.0} & \multicolumn{2}{|l|}{3017.0} & \multicolumn{2}{|l|}{3022.3} \\
\hline$\nu\left(\mathrm{C} 9-\mathrm{H}_{3}\right)^{\prime \prime}$ as & 3124.6 & 14.6 & \multicolumn{2}{|l|}{3014.5} & \multicolumn{2}{|l|}{3004.5} & \multicolumn{2}{|l|}{3009.6} \\
\hline$\nu\left(\mathrm{C} 5-\mathrm{H}_{3}\right)^{\prime \prime}{ }_{\text {as }}$ & 3089.4 & 22.8 & \multicolumn{2}{|l|}{3005.1} & \multicolumn{2}{|l|}{2994.9} & \multicolumn{2}{|l|}{3003.9} \\
\hline$\nu\left(\mathrm{C} 9-\mathrm{H}_{3}\right)_{s}$ & 3048.0 & 30.4 & \multicolumn{2}{|l|}{2960.5} & \multicolumn{2}{|l|}{2945.3} & \multicolumn{2}{|l|}{$2969.5 / 2945.4$} \\
\hline$\nu\left(\mathrm{C} 5-\mathrm{H}_{3}\right)_{s}$ & 3024.2 & 41.6 & \multicolumn{2}{|l|}{2955.1} & \multicolumn{2}{|l|}{2939.0} & \multicolumn{2}{|l|}{$2935.2 / 2928.8$} \\
\hline$\delta\left(\mathrm{C} 9-\mathrm{H}_{3}\right)^{\prime}$ as & 1509.5 & 4.8 & \multicolumn{2}{|l|}{1469.1} & \multicolumn{2}{|l|}{1466.1} & \multicolumn{2}{|l|}{1462.4} \\
\hline$\delta\left(\mathrm{C} 5-\mathrm{H}_{3}\right)^{\prime \prime}$ as & 1504.8 & 13.4 & \multicolumn{2}{|l|}{1464.5} & \multicolumn{2}{|l|}{1461.5} & 1458.5 & \\
\hline$\delta\left(\mathrm{C} 5-\mathrm{H}_{3}\right)^{\prime}{ }_{\text {as }}$ & 1492.0 & 9.3 & 1455.7 & & 1453.7 & & 1449.9 & \\
\hline$\delta\left(\mathrm{C} 9-\mathrm{H}_{3}\right)^{\prime \prime}$ as & 1485.7 & 7.9 & 1451.3 & & 1451.7 & & 1445.7 & \\
\hline$\delta\left(\mathrm{C} 5-\mathrm{H}_{3}\right)_{s}$ & 1467.9 & 0.3 & 1446.8 & & 1448.7 & & 1442.9 & \\
\hline$\delta\left(\mathrm{C} 9-\mathrm{H}_{3}\right)_{s}$ & 1458.7 & 0.3 & 1428.9 & & 1426.0 & & Not observed & \\
\hline$\nu(\mathrm{S}=\mathrm{O})$ & 1231.7 & 151.6 & 1233.2 & 1231.8 & 1230.6 & 1229.2 & 1227.5 & 1225.9 \\
\hline$\gamma\left(\mathrm{C} 5-\mathrm{H}_{3}\right)^{\prime}$ & 1188.5 & 9.3 & 1185.4 & & 1185.2 & & & \\
\hline$\gamma\left(\mathrm{C} 9-\mathrm{H}_{3}\right)^{\prime}$ & 1178.8 & 0.7 & Not observed & & Not observed & & & \\
\hline$\gamma\left(\mathrm{C} 5-\mathrm{H}_{3}\right)^{\prime \prime}$ & 1174.6 & 0.7 & Not observed & & Not observed & & & \\
\hline$\gamma\left(\mathrm{C} 9-\mathrm{H}_{3}\right)^{\prime \prime}$ & 1169.8 & 2.2 & 1165.7 & & 1165.5 & & & \\
\hline$\nu(\mathrm{C} 5-\mathrm{O})$ & 1017.5 & 59.1 & 1009.7 & 1009.2 & 1005.4 & & & \\
\hline$\nu(\mathrm{C} 9-\mathrm{O})$ & 981.1 & 99.2 & 972.1 & 975.6 & 972.3 & 971.0 & 969.2 & \\
\hline$\gamma(\mathrm{S}=\mathrm{O})$ & 707.7 & 10.5 & 733.2 & 730.8 & 728.0 & 729.8 & 724.7 & $728.8 / 727.1$ \\
\hline$\nu(\mathrm{S}-\mathrm{O} 2)$ & 661.1 & 36.6 & $693.8 / 688.5$ & $\begin{array}{l}692.1 / 690.7 / \\
689.1\end{array}$ & 687.1 & 691.7 & 684.8 & 690.8 \\
\hline$\nu(\mathrm{S}-\mathrm{O} 3)$ & 563.3 & 7.0 & 578.2 & & 576.1 & & 580.0 & \\
\hline$\delta(\mathrm{OSO})$ & 427.0 & 1.1 & Not observed & & Not observed & & Not observed & \\
\hline$\delta(\mathrm{S}=\mathrm{O})$ & 401.5 & 7.4 & & & & & & \\
\hline$\delta(\mathrm{S}-\mathrm{O} 3-\mathrm{C} 9)$ & 250.3 & 12.0 & & & & & & \\
\hline$\delta(\mathrm{S}-\mathrm{O} 2-\mathrm{C} 5)$ & 241.8 & 1.1 & & & & & & \\
\hline$\tau(\mathrm{S}-\mathrm{O} 3)$ & 138.3 & 4.1 & Not investigat & & Not investiga & & Not investiga & \\
\hline$\tau\left(\mathrm{C} 5-\mathrm{H}_{3}\right)$ & 91.3 & 1.0 & & & & & & \\
\hline$\tau\left(\mathrm{C} 9-\mathrm{H}_{3}\right)$ & 84.6 & 0.3 & & & & & & \\
\hline$\tau(\mathrm{S}-\mathrm{O} 2)$ & 77.3 & 2.4 & & & & & & \\
\hline
\end{tabular}

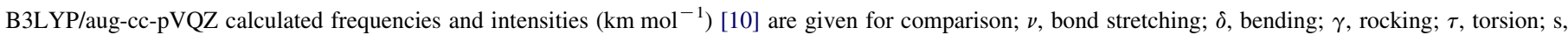
symmetric; as, asymmetric. See Ref. [10] for definition of internal coordinates and Fig. 1 for atom numbering.

In addition, the relative population of GT increases relatively to that of $\mathrm{GG}^{\prime}$ in going from $\mathrm{Ar}$ to $\mathrm{Kr}$ (as already mentioned, in $\mathrm{Xe}$, no $\mathrm{GG}^{\prime}$ bands are observed). These results unequivocally prove that the $\mathrm{GG}^{\prime} \rightarrow \mathrm{GT}$ isomerization took place during deposition of the various matrices at $10 \mathrm{~K}$, decreasing in importance from Xe (where it occurs completely) to Ar. There are, however, some additional conclusions that can be extracted from the data shown in Fig. 3, that are subtler:

The relative populations of the conformers at $298 \mathrm{~K}$, estimated from the theoretical calculations (assuming the Boltzmann distribution and using the DFT(B3LYP)/aug-ccpVQZ calculated relative conformational energies) are GG: $48.8 \%, \mathrm{GT}+\mathrm{GG}^{\prime}: 35.0+15.1=50.1 \%$. On the other hand, the experimental values obtained for the argon matrix are GG: $36 \%, \mathrm{GT}+\mathrm{GG}^{\prime}: 37+27=64 \%$. In krypton, the corresponding values are GG: $42 \%, \mathrm{GT}+\mathrm{GG}^{\prime}: 54+4=58 \%$. Hence, the results seem to indicate that the calculations slightly overestimate the energy of at least one of the higher energy conformers $\left(\mathrm{GT}, \mathrm{GG}^{\prime}\right)$ comparatively to $\mathrm{GG}$ (the sum of the calculated populations of GT and $\mathrm{GG}^{\prime}$ is consistently smaller than the experimental values). In addition, the results also point to occurrence in small amount of $\mathrm{GT} \rightarrow \mathrm{GG}$ isomerization during deposition of the $\mathrm{Kr}$ matrix (as already mentioned, $\mathrm{Kr}$ is a more relaxant gas than Ar). On the other hand, with all probability, this process does not occur during deposition of argon matrix at $10 \mathrm{~K}$.

In the $10 \mathrm{~K}$ as-deposited xenon matrix, the population of the most stable GG form, though comparable to those observed in Ar and $\mathrm{Kr}$ matrices, was found to be slightly smaller than in these two latter matrices (30 vs. $36 \%$ in argon and $42 \%$ in krypton). At first, this result appeared somewhat surprising, since it could be expected the population of this form to increase slightly relatively to what was found in $\mathrm{Kr}$ (xenon being a better relaxant than $\mathrm{Kr}$ could eventually led to increase the possibility of occurrence of the GT $\rightarrow$ GG process during deposition of the $\mathrm{Xe}$ matrix when compared to $\mathrm{Kr}$ ). An explanation for this observation could only be obtained after recording of spectra in the various matrices using higher substrate temperatures during deposition. Fig. 4 shows the relative conformational populations estimated as previously from data collected for a substrate temperature of $30 \mathrm{~K}$ in matrices of the three support-gases used. As it can be seen from this figure, according to the expectations, at this substrate temperature both $\mathrm{GG}^{\prime} \rightarrow \mathrm{GT}$ and $\mathrm{GT} \rightarrow \mathrm{GG}$ processes occur 
Table 2

Observed frequencies $\left(\mathrm{cm}^{-1}\right)$ for the GT form of dimethyl sulfite monomer in argon, krypton and xenon matrices

\begin{tabular}{|c|c|c|c|c|c|c|c|c|}
\hline \multirow{2}{*}{$\begin{array}{l}\text { Approximate } \\
\text { description }\end{array}$} & \multirow{2}{*}{$\begin{array}{l}\text { Calculated fre- } \\
\text { quency }\end{array}$} & \multirow{2}{*}{$\begin{array}{l}\text { Calculated } \\
\text { intensity }\end{array}$} & \multicolumn{2}{|c|}{ Observed frequency $\operatorname{Ar}(10 \mathrm{~K})$} & \multicolumn{2}{|c|}{ Observed frequency $\mathrm{Kr}(10 \mathrm{~K})$} & \multicolumn{2}{|c|}{ Observed Frequency Xe (10 K) } \\
\hline & & & $\begin{array}{l}\text { More stable } \\
\text { site }\end{array}$ & $\begin{array}{l}\text { Less stable } \\
\text { sites }\end{array}$ & $\begin{array}{l}\text { More stable } \\
\text { site }\end{array}$ & $\begin{array}{l}\text { Less stable } \\
\text { sites }\end{array}$ & $\begin{array}{l}\text { More stable } \\
\text { site }\end{array}$ & $\begin{array}{l}\text { Less stable } \\
\text { sites }\end{array}$ \\
\hline$\nu\left(\mathrm{C} 5-\mathrm{H}_{3}\right)^{\prime}$ as & 3150.4 & 7.3 & 3028.0 & & 3017.0 & & 3022.3 & \\
\hline$\nu\left(\mathrm{C} 5-\mathrm{H}_{3}\right)^{\prime \prime}$ as & 3135.1 & 8.8 & 3028.0 & & 3017.0 & & 3022.3 & \\
\hline$\nu\left(\mathrm{C} 9-\mathrm{H}_{3}\right)^{\prime}$ as & 3134.1 & 10.0 & 3028.0 & & 3017.0 & & 3022.3 & \\
\hline$\nu\left(\mathrm{C} 9-\mathrm{H}_{3}\right)^{\prime \prime}$ as & 3095.4 & 19.4 & 3005.1 & & 2994.9 & & 3003.9 & \\
\hline$\nu\left(\mathrm{C} 5-\mathrm{H}_{3}\right)_{s}$ & 3055.2 & 30.2 & 2960.5 & & 2945.3 & & $2969.5 / 2945.4$ & \\
\hline$\nu\left(\mathrm{C} 9-\mathrm{H}_{3}\right)_{s}$ & 3020.8 & 49.3 & 2952.8 & & 2939.0 & & $2935.2 / 2928.8$ & \\
\hline$\delta\left(\mathrm{C} 9-\mathrm{H}_{3}\right)^{\prime}$ as & 1508.1 & 14.4 & 1469.1 & & 1466.1 & & 1462.4 & \\
\hline$\delta\left(\mathrm{C} 5-\mathrm{H}_{3}\right)^{\prime \prime}{ }_{\text {as }}$ & 1507.3 & 6.8 & 1467.8 & & 1463.6 & & 1458.5 & \\
\hline$\delta\left(\mathrm{C} 9-\mathrm{H}_{3}\right)^{\prime \prime}{ }_{\text {as }}$ & 1492.6 & 7.5 & 1457.6 & & 1456.6 & & 1449.9 & \\
\hline$\delta\left(\mathrm{C} 5-\mathrm{H}_{3}\right)^{\prime}$ as & 1489.5 & 7.9 & 1454.0 & & 1452.6 & & 1445.7 & \\
\hline$\delta\left(\mathrm{C} 9-\mathrm{H}_{3}\right)_{s}$ & 1468.8 & 0.3 & 1446.8 & & 1448.7 & & 1442.9 & \\
\hline$\delta\left(\mathrm{C} 5-\mathrm{H}_{3}\right)_{s}$ & 1459.0 & 0.4 & 1428.9 & & 1426.0 & & Not observed & \\
\hline$\nu(\mathrm{S}=\mathrm{O})$ & 1206.0 & 150.0 & $1208.6 / 1207.0$ & $\begin{array}{l}1211.7 / 1211.2 \\
1209.7\end{array}$ & 1210.1 & $1209.1 / 1206.8$ & 1203.3 & $1206.5 / 1204.5$ \\
\hline$\gamma\left(\mathrm{C} 9-\mathrm{H}_{3}\right)^{\prime}$ & 1189.5 & 3.3 & 1189.6 & & 1189.2 & & 1194.4 & \\
\hline$\gamma\left(\mathrm{C} 5-\mathrm{H}_{3}\right)^{\prime}$ & 1183.3 & 5.1 & 1187.9 & & 1186.7 & & 1185.8 & 1182.6 \\
\hline$\gamma\left(\mathrm{C} 9-\mathrm{H}_{3}\right)^{\prime \prime}$ & 1175.9 & 2.8 & Not observed & & Not observed & & Not observed & \\
\hline$\gamma\left(\mathrm{C} 5-\mathrm{H}_{3}\right)^{\prime \prime}$ & 1168.7 & 1.9 & Not observed & & Not observed & & Not observed & \\
\hline$\nu(\mathrm{C} 9-\mathrm{O})$ & 1021.2 & 131.5 & 1016.6 & $1018.8 / 1012.3$ & 1011.8 & $1015.7 / 1014.2$ & 1005.4 & $1009.9 / 1007.6$ \\
\hline$\nu(\mathrm{C} 5-\mathrm{O})$ & 982.7 & 249.1 & 980.1 & & $979.3 / 978.3$ & & 973.3 & \\
\hline$\nu(\mathrm{S}-\mathrm{O} 2)$ & 727.5 & 86.2 & $748.3 / 747.3$ & $750.1 / 746.9$ & 745.5 & 747.4 & 746.4 & $747.5 / 744.9$ \\
\hline$\nu(\mathrm{S}-\mathrm{O} 3)$ & 664.6 & 225.3 & 696.9 & Not observed & 696.2 & 693.7 & 699.6 & 692.7 \\
\hline$\gamma(\mathrm{S}=\mathrm{O})$ & 566.1 & 15.5 & 578.2 & & 576.1 & & 580.0 & \\
\hline$\delta(\mathrm{S}=\mathrm{O})$ & 456.8 & 2.5 & Not observed & & Not observed & & Not observed & \\
\hline$\delta(\mathrm{OSO})$ & 383.8 & 5.7 & & & & & & \\
\hline$\delta(\mathrm{S}-\mathrm{O} 2-\mathrm{C} 5)$ & 278.6 & 4.9 & & & & & & \\
\hline$\delta(\mathrm{S}-\mathrm{O} 3-\mathrm{C} 9)$ & 218.8 & 6.4 & & & & & & \\
\hline$\tau\left(\mathrm{C} 9-\mathrm{H}_{3}\right)$ & 141.6 & 4.2 & Not investigated & & Not investigated & & Not investigated & \\
\hline$\tau\left(\mathrm{C} 5-\mathrm{H}_{3}\right)$ & 121.7 & 2.5 & & & & & & \\
\hline$\tau(\mathrm{S}-\mathrm{O} 2)$ & 93.2 & 4.3 & & & & & & \\
\hline$\tau(\mathrm{S}-\mathrm{O} 3)$ & 72.8 & 3.4 & & & & & & \\
\hline
\end{tabular}

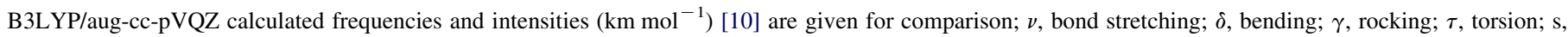
symmetric; as, asymmetric. See Ref. [10] for definition of internal coordinates and Fig. 1 for atom numbering.

extensively during deposition of the $\mathrm{Ar}$ and $\mathrm{Kr}$ matrices and the population of the most stable GG form is $100 \%$ in the $\mathrm{Kr}$ matrix and nearly this value in the less relaxant Ar matrix. However, the situation was found to be dramatically different in the xenon matrix, with the GT/GG population ratio being approximately the same as obtained for matrices deposited at $10 \mathrm{~K}$ (and also other temperatures between 10 and $30 \mathrm{~K}$ ). Such behavior cannot be explained in terms of conformational cooling, since the GG form is the most stable conformer in the matrix. Indeed, an inversion in the relative stability of the GG and GT conformers in this matrix, when compared to the other matrices (and also to the gaseous phase), looks very improbable, since GT is the less polar conformer and shall in fact be somewhat destabilized in the most polarizable xenon matrix (calculated dipole moments are 3.91, 2.00 and 2.67 debye for GG, GT and $\mathrm{GG}^{\prime}$, respectively [10]). The observations can however be easily explained assuming that aggregation is taking place during deposition of the xenon matrices, with the most polar GG form showing a greater trend to associate than the remaining (less polar) conformers. This effect would then mask the effect of conformational cooling during deposition of the Xe matrices, i.e. because the GG form aggregates easier than the GT form, its population reduces relatively to that of the latter conformer. Naturally, this effect must be more pronounced for higher substrate temperatures and, as result of simultaneous occurrence of the two processes (conformational cooling, leading to increase the population of GG, and conformationally selective aggregation, leading to reduce it relatively to that of GT), the GT/GG population ratio stays nearly invariant within the temperature range covered by our experiments. The fact that the GG population observed in the as-deposited $10 \mathrm{~K}$ xenon matrix is slightly smaller than in the as-deposited $10 \mathrm{~K}$ krypton and argon matrices is then an indication that even at this temperature some aggregation of the compound is taking place. Very unfortunately, in xenon matrices aggregates usually give rise to very broad bands, which most of times are not possible to discriminate from the baseline [20]. For a relatively small amount of aggregates, as expected in the present case for the Xe matrices deposited at the lowest substrate temperatures, observation of these bands would be highly improbable. Formation of aggregates is, however, quite clear in Xe matrices for higher temperatures of deposition (Fig. 5), and, symptomatically, systematically more important, at a given temperature, than in both $\mathrm{Ar}$ and $\mathrm{Kr}$ 
Table 3

Observed frequencies $\left(\mathrm{cm}^{-1}\right)$ for the $\mathrm{GG}^{\prime}$ form of dimethyl sulfite monomer in argon and krypton matrices. B3LYP/aug-cc-pVQZ calculated frequencies and intensities $\left(\mathrm{km} \mathrm{mol}^{-1}\right)[10]$ are given for comparison

\begin{tabular}{|c|c|c|c|c|c|c|}
\hline \multirow{2}{*}{$\begin{array}{l}\text { Approximate } \\
\text { description }\end{array}$} & \multirow{2}{*}{$\begin{array}{l}\text { Calculated } \\
\text { frequency }\end{array}$} & \multirow[t]{2}{*}{ Calculated intensity } & \multicolumn{2}{|c|}{ Observed frequency $\operatorname{Ar}(10 \mathrm{~K})$} & \multicolumn{2}{|c|}{ Observed Frequency $\mathrm{Kr}(10 \mathrm{~K})$} \\
\hline & & & More stable site & Less stable sites & More stable site & Less stable sites \\
\hline$\nu\left(\mathrm{CH}_{3}\right)^{\prime}{ }_{\mathrm{as}} s$ & 3138.0 & 3.4 & 3028.0 & & 3017.0 & \\
\hline$\nu\left(\mathrm{CH}_{3}\right)^{\prime}$ as as & 3137.3 & 8.7 & 3028.0 & & 3017.0 & \\
\hline$\nu\left(\mathrm{CH}_{3}\right)^{\prime \prime}$ as $s$ & 3116.3 & 12.8 & 2986.0 & & 2978.8 & \\
\hline$\nu\left(\mathrm{CH}_{3}\right)^{\prime \prime}$ as as & 3113.5 & 25.1 & 2986.0 & & 2978.8 & \\
\hline$\nu\left(\mathrm{CH}_{3}\right)_{\mathrm{s}} s$ & 3041.4 & 62.3 & 2960.5 & & 2959.5 & \\
\hline$\nu\left(\mathrm{CH}_{3}\right)_{\mathrm{s}}$ as & 3037.5 & 9.4 & 2960.5 & & 2959.5 & \\
\hline$\delta\left(\mathrm{CH}_{3}\right)^{\prime}$ as $s$ & 1508.9 & 2.9 & 1469.1 & & 1466.1 & \\
\hline$\delta\left(\mathrm{CH}_{3}\right)^{\prime \prime}$ as $s$ & 1501.5 & 9.4 & 1460.5 & & 1458.9 & \\
\hline$\delta\left(\mathrm{CH}_{3}\right)^{\prime}$ as as & 1500.1 & 16.3 & 1460.5 & & 1458.9 & \\
\hline$\delta\left(\mathrm{CH}_{3}\right)^{\prime \prime}$ as as & 1491.1 & 2.9 & 1455.7 & & 1453.7 & \\
\hline$\delta\left(\mathrm{CH}_{3}\right)_{\mathrm{s}} s$ & 1461.9 & 2.1 & 1428.9 & & 1426.0 & \\
\hline$\delta\left(\mathrm{CH}_{3}\right)_{\mathrm{s}}$ as & 1454.8 & 0.3 & 1422.7 & & 1420.7 & \\
\hline$\nu(\mathrm{S}=\mathrm{O})$ & 1195.7 & 122.3 & 1197.7 & $1202.9 / 1199.7$ & 1198.0 & 1196.6/1195.6 \\
\hline$\gamma\left(\mathrm{CH}_{3}\right)^{\prime}$ as & 1183.3 & 0.9 & Not observed & & Not observed & \\
\hline$\gamma\left(\mathrm{CH}_{3}\right)^{\prime} s$ & 1182.1 & 16.4 & 1180.4 & & 1181.3 & \\
\hline$\gamma\left(\mathrm{CH}_{3}\right)^{\prime \prime}$ as & 1167.6 & 0.9 & Not observed & & Not observed & \\
\hline$\gamma\left(\mathrm{CH}_{3}\right)^{\prime \prime} s$ & 1165.9 & 4.9 & 1165.8 & & 1165.5 & \\
\hline$\nu(\mathrm{C}-\mathrm{O}) \mathrm{s}$ & 1007.3 & 197.5 & 1006.9 & & 1001.7 & \\
\hline$\nu(\mathrm{C}-\mathrm{O})^{\prime \prime}$ as & 973.2 & 160.0 & 965.7 & & 971.0 & \\
\hline$\nu(\mathrm{S}-\mathrm{O}) s$ & 679.7 & 79.8 & 698.3 & 699.1 & 698.2 & 700.0 \\
\hline$\nu(\mathrm{S}-\mathrm{O})^{\prime \prime}$ as & 651.2 & 266.7 & 682.2 & $\begin{array}{l}685.0 / 683.7 / 680.1 / \\
677.5\end{array}$ & 682.3 & 685.5 \\
\hline$\gamma(\mathrm{S}=\mathrm{O})$ & 599.2 & 15.3 & 615.3 & & 616.4 & \\
\hline$\delta(\mathrm{S}=\mathrm{O})$ & 479.3 & 0.0 & Not observed & & Not observed & \\
\hline$\delta(\mathrm{OSO})$ & 354.1 & 7.6 & & & & \\
\hline$\delta(\mathrm{SOC})$ as & 273.5 & 12.5 & & & & \\
\hline$\delta(\mathrm{SOC}) s$ & 266.1 & 11.4 & & & & \\
\hline$\tau\left(\mathrm{CH}_{3}\right)$ as & 144.2 & 1.8 & Not investigated & & Not investigated & \\
\hline$\tau(\mathrm{S}-\mathrm{O})$ as & 93.9 & 2.2 & & & & \\
\hline$\tau\left(\mathrm{CH}_{3}\right) s$ & 84.3 & 0.0 & & & & \\
\hline$\tau(\mathrm{S}-\mathrm{O}) s$ & 44.2 & 0.7 & & & & \\
\hline
\end{tabular}

$\nu$, Bond stretching; $\delta$, bending; $\gamma$, rocking; $\tau$, torsion; $s$, symmetric; as, asymmetric. See Ref. [10] for definition of internal coordinates and Fig. 1 for atom numbering.

matrices. It is worth noting that conformation selective aggregation has been found to occur in different compounds, and matrix isolation infrared spectroscopy has been shown to constitute a powerful technique to probe such phenomenon $[15,20]$.

In our previous study on $\mathrm{DMSO}_{3}$ [10], we had already shown that annealing of the argon matrix deposited at $15 \mathrm{~K}$ to higher temperatures led to spectral changes which are consistent with occurrence of $\mathrm{GG}^{\prime} \rightarrow \mathrm{GT}$ isomerization within the temperature range $15-21 \mathrm{~K}$ while the GT $\rightarrow$ GG processes started to occur significantly only for a temperature higher than $21 \mathrm{~K}$. As mentioned above, the different triggering temperatures for these two processes are a direct consequence of the different energy barriers associated with them (1.90 and $9.64 \mathrm{~kJ} \mathrm{~mol}^{-1}$, respectively). The consecutive nature of the isomerization processes could also now be unequivocally established for the krypton matrices, as shown by the change in the relative intensity of the $\nu \mathrm{S}=\mathrm{O}$ bands as a function of the substrate temperature during deposition. Fig. 6 shows the data obtained for substrate temperatures of 10,20 and $30 \mathrm{~K}$. The spectra were normalized by the band of the less stable $\mathrm{Kr}$

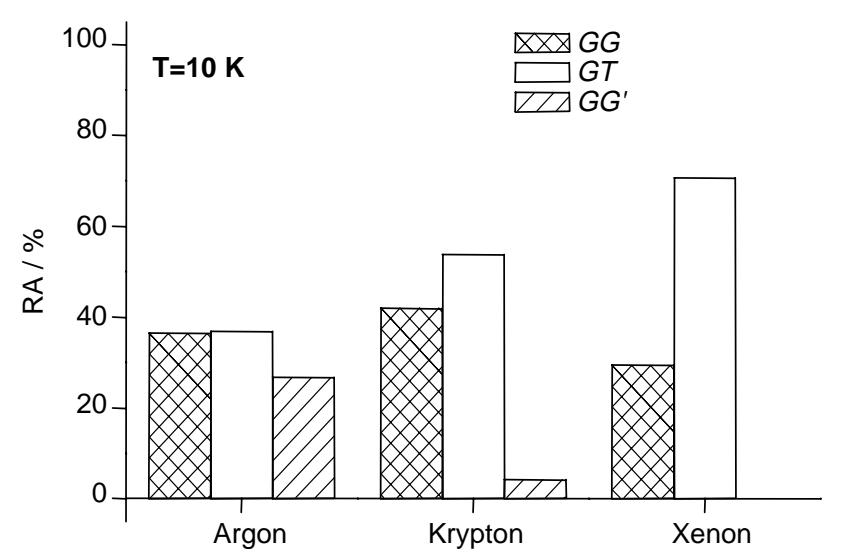

Fig. 3. Graph bar showing the experimental relative abundances (RA) of GG, GT and $\mathrm{GG}^{\prime}$ conformers trapped in argon, krypton and xenon matrices using a substrate temperature during deposition of $10 \mathrm{~K}$. The populations were estimated from the integral intensity of the bands in the $1250-1180 \mathrm{~cm}^{-1}$ $(\nu \mathrm{S}=\mathrm{O})$, weighted by the corresponding calculated [DFT(B3LYP)/aug-ccpVQZ] intensities. 


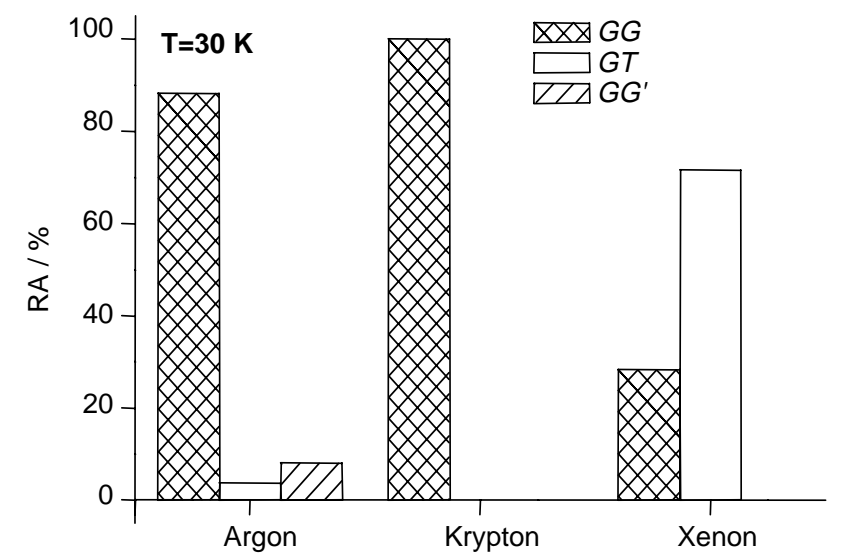

Fig. 4. Graph bar showing the experimental relative abundances (RA) of GG, GT and $\mathrm{GG}^{\prime}$ conformers trapped in argon, krypton and xenon matrices using a substrate temperature during deposition of $30 \mathrm{~K}$. The populations were estimated from the integral intensity of the bands in the $1250-1180 \mathrm{~cm}^{-1}$ $(\nu \mathrm{S}=\mathrm{O})$, weighted by the corresponding calculated [DFT(B3LYP)/aug-ccpVQZ] intensities.

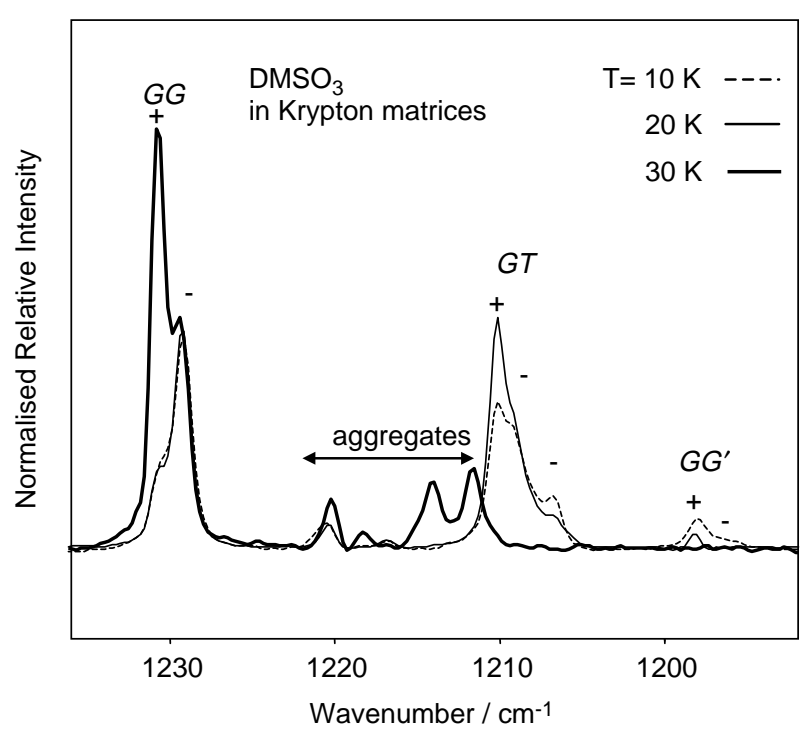

Fig. 6. The $\mathrm{S}=\mathrm{O}$ stretching region of the infrared spectra of $\mathrm{DMSO}_{3}$ isolated in krypton matrices using different substrate temperatures. The temperature of the optical substrate during deposition of the samples was kept at $10 \mathrm{~K}$ (dashed line), $20 \mathrm{~K}$ (thin solid line) and $30 \mathrm{~K}$ (thick solid line). The spectra were normalized to the intensity of the GG band at $1231.8 \mathrm{~cm}^{-1}$. Signs ( + and - ) refer to bands originated in the most stable and less stable matrix-sites, respectively (see also Tables 1-3).

matrix site of GG, at $1229.2 \mathrm{~cm}^{-1}$. From this figure, it can be easily noticed that until a substrate temperature of ca. $20 \mathrm{~K}$ conformer $\mathrm{GG}^{\prime}$ converts into form GT (simultaneously, intersite conversion led to the conversion of GT $\mathrm{Kr}$ matrix less stable sites-giving rise to the bands at 1209.1 and $1206.8 \mathrm{~cm}^{-1}$-into the most stable site-associated with the band at $1210.1 \mathrm{~cm}^{-1}$ ). When deposition was made with substrate temperatures above ca. $20 \mathrm{~K}$, conversion of GT into GG occurs, leading to disappearance of the bands due to GT and relative increase of the band of the most stable site of GG at $1230.6 \mathrm{~cm}^{-1}$. It is interesting to note that the $\mathrm{GT} \rightarrow \mathrm{GG}$

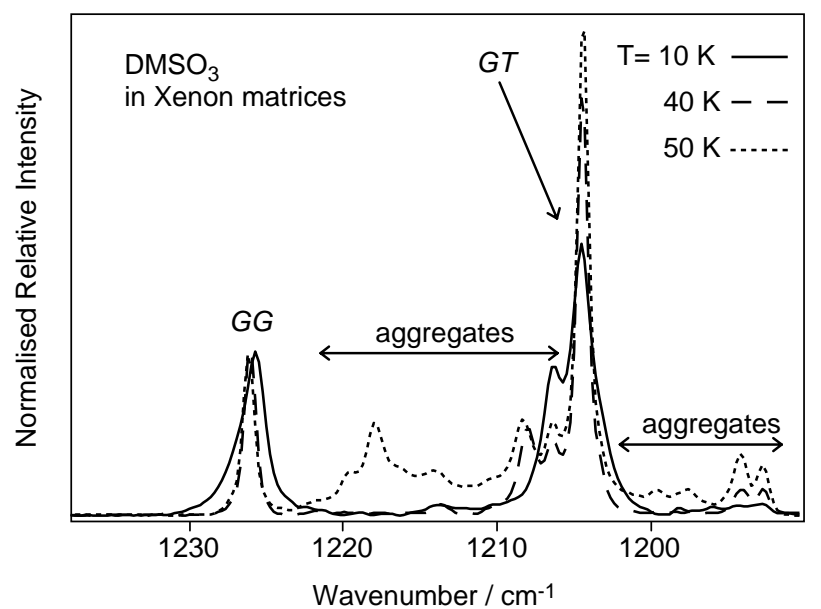

Fig. 5. The $\mathrm{S}=\mathrm{O}$ stretching region of the infrared spectra of $\mathrm{DMSO}_{3}$ isolated in xenon matrices using different substrate temperatures during deposition: 10, 40 and $50 \mathrm{~K}$. The spectra were normalized to the total intensity of the features ascribed to the GG form.

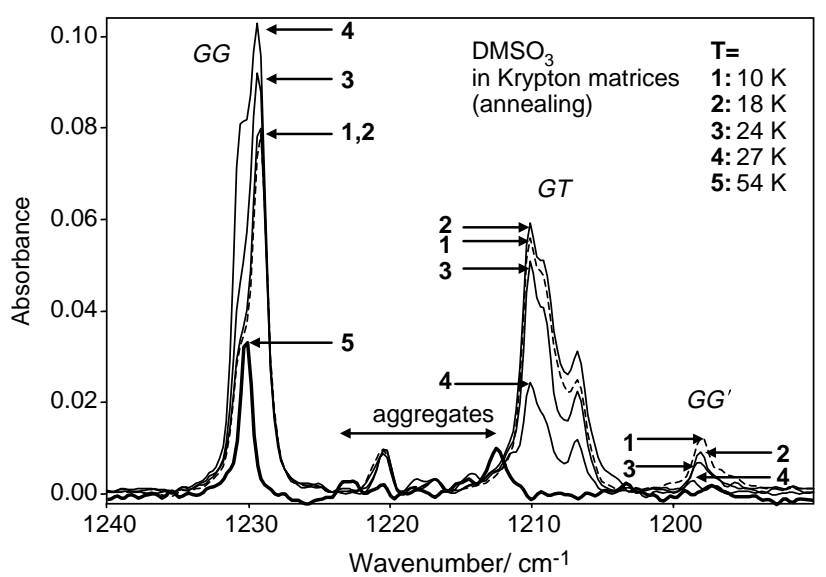

Fig. 7. The $\mathrm{S}=\mathrm{O}$ stretching region of the infrared spectrum of $\mathrm{DMSO}_{3}$ isolated in krypton matrices. The temperature of the optical substrate during deposition of the sample was kept at $10 \mathrm{~K}$ (dashed line-trace 1). The remaining traces (2-5) correspond to spectra obtained at different temperatures during the annealing of the matrix.

conversion leads to the production of GG form in its most stable site. The same seems to be true also for the production of GT from $\mathrm{GG}^{\prime}$, though in this case the results are not so clear due to occurrence of important simultaneous inter-site conversion of GT (and also because the amount of $\mathrm{GG}^{\prime}$ initially trapped in the $\mathrm{Kr}$ matrices is small).

As it could be anticipated, the results of the annealing of the matrices after deposition resemble very much those obtaining in the series of experiments discussed above where the deposition temperature was varied. Fig. 7 shows the results obtained in krypton, that also closely follow those previously obtained for the compound isolated in argon [10]. In the temperature range $10-18 \mathrm{~K}$, essentially two phenomena are observed: $\mathrm{GG}^{\prime} \rightarrow \mathrm{GT}$ isomerization and inter-site conversion of GT (compare traces 1 and 2 in Fig. 7). The features due to $\mathrm{GG}^{\prime}$ and GT decrease and increase in intensity, respectively, while 
those due to GG do not change. At $24 \mathrm{~K}$ (trace 3 in Fig. 7), the GT $\rightarrow$ GG conversion has already started and, consequently, the bands due to GG increase in intensity at expenses of those due to GT (the $\mathrm{GG}^{\prime} \rightarrow \mathrm{GT}$ isomerization continues to occur leading to a continued decrease in intensity of the bands due to $\mathrm{GG}^{\prime}$ ). At $27 \mathrm{~K}$ (trace 4 in Fig. 7) the $\mathrm{GG}^{\prime} \rightarrow \mathrm{GT}$ isomerization was practically completed and the GT $\rightarrow G G$ process has also occurred in large extension. Finally, at $54 \mathrm{~K}$ (trace 5), both processes were concluded while aggregation has also occurred extensively (only the most stable matrix site of the GG monomer is still somewhat populated).

\section{Conclusion}

Conformational cooling occurring both during and after deposition of $\mathrm{DMSO}_{3}$ in cryogenic matrices of $\mathrm{Ar}, \mathrm{Kr}$ and $\mathrm{Xe}$ has been analyzed. As it has been also observed for other compounds [12-18], the degree of the conformational cooling depends on the nature of the matrix gas host, being more important along the series $\mathrm{Xe}>\mathrm{Kr}>\mathrm{Ar}$.

The low energy barrier for the $\mathrm{GG}^{\prime} \rightarrow \mathrm{GT}$ conversion $\left(1.90 \mathrm{~kJ} \mathrm{~mol}^{-1}\right)$ allows that extensive isomerization of the $\mathrm{GG}^{\prime}$ into the GT conformer take place during deposition of the matrices. In xenon, $\mathrm{GG}^{\prime}$ completely converts to GT during deposition even at a temperature as low as $10 \mathrm{~K}$. On the other hand, the GT $\rightarrow$ GG process has a considerably higher energy barrier $\left(9.64 \mathrm{~kJ} \mathrm{~mol}^{-1}\right)$ and conversion of GT into GG occurs only when deposition of the matrix is performed at higher temperatures (higher than ca. $20 \mathrm{~K}$ ). Very interestingly, this process leads to formation of GG into its most stable matrixsite. Identical situation does also probably occur relatively to GT formed in the $\mathrm{GG}^{\prime} \rightarrow \mathrm{GT}$ process, though the extensive inter-site conversion for $\mathrm{GT}$ and $\mathrm{GG}^{\prime}$ led us to consider this conclusion only as tentative. The annealing experiments performed in both argon and krypton matrices strongly supported the results obtained in the experiments where the substrate temperature was varied, regarding the consecutive nature of the two isomerization processes investigated.

When compared with the other two types of matrices, the results obtained in xenon were not so successful in the study of the conformational isomerization processes. Firstly, because no $\mathrm{GG}^{\prime}$ conformer could be trapped in the Xe matrices due to fast conversion to GT. Secondly, because aggregation was found to be considerably more important in this case. However, from these studies it was possible to conclude about the different ability of the conformers to aggregate. It was found that $\mathrm{DMSO}_{3}$ exhibits conformation selective aggregation capabilities, with the most polar GG conformer exhibiting a greater ability to aggregate than the remaining forms.

\section{Acknowledgements}

The authors acknowledge the Portuguese Science Foundation (FCT_POCTI/QUI/59019/2004 and POCTI/QUI/58937), GRICES/SECyT (PO/PA04-EVI/001//00813 and PO/PA04-EIX/018//00812), 'Instituto de Investigação Interdisciplinar' of the University of Coimbra (III/BIO/40/2005), FEDER and the Argentinian Agencia Nacional de Promoción Científica y Tecnológica (PICT 13080) for financial support. A.G.-Z. and A.B thank FCT also for the Grants SFRH/BPD/11499/2002 and SRHM/BD/21543/2005, respectively.

\section{References}

[1] H. Woerden, Chem. Rev. 63 (1963) 557.

[2] A. Gawienowski, M. Stacewicz-Sapuntzakis, Behav. Biol. 23 (1978) 267.

[3] J. Grabowski, R. Lum, J. Am. Chem. Soc. 112 (1990) 607.

[4] L. Cazaux, J.D. Bastide, G. Chassaing, P. Maroni, Spectrochim. Acta, Part A 35 (1979) 15 .

[5] L. Cazaux, G. Chassaing, P. Maroni, Spectrochim. Acta, Part A 40 (1984) 519.

[6] A.B. Remizov, A.I. Fishman, I.S. Pominov, Spectrochim. Acta, Part A 35 (1979) 901.

[7] P. Klaeboe, Acta Chem. Scand. 22 (1968) 2817.

[8] R.L. Odeurs, B.J. Van der Veken, M.A. Herman, J. Mol. Struct. 79 (1982) 451.

[9] A.J. Barnes, B.J. Van der Veken, J. Mol. Struct. 157 (1987) 119.

[10] A. Borba, A. Gómez-Zavaglia, P.N.N.L. Simões, R. Fausto, J. Phys. Chem. A 109 (2005) 3578.

[11] A.J. Barnes, J. Mol. Struct. 113 (1984) 161.

[12] I.D. Reva, S. Stepanian, L. Adamowicz, R. Fausto, J. Phys. Chem. A 107 (2003) 6351.

[13] I.D. Reva, S. Stepanian, L. Adamowicz, R. Fausto, Chem. Phys. Lett. 374 (2003) 631.

[14] I. Reva, S. Ilieva, R. Fausto, Phys. Chem. Chem. Phys. 3 (2001) 4235.

[15] A. Gómez-Zavaglia, R. Fausto, Phys. Chem. Chem. Phys. 5 (2003) 52.

[16] Y. Grenie, C. Garrigou-Lagrange, J. Mol. Spectrosc. 41 (1972) 240.

[17] I.D. Reva, A. Plokhotnichenko, S. Stepanian, A.Yu. Ivanov, E. Radchenko, G. Sheina, Yu.P. Blagoi, Chem. Phys. Lett. 232 (1995) 141; I.D. Reva, A. Plokhotnichenko, S. Stepanian, A.Yu. Ivanov, E. Radchenko, G. Sheina, Yu.P. Blagoi, Chem. Phys. Lett. 235 (1995) 617 Erratum.

[18] S. Stepanian, I.D. Reva, E. Radchenko, M.T.S. Rosado, M.L.T.S. Duarte, R. Fausto, L. Adamowicz, J. Phys. Chem. A 102 (1998) 1041.

[19] A. Borba, A. Gómez-Zavaglia, P.N.N.L. Simões, R. Fausto, Spectrochim. Acta, Part A 61 (2005) 1461

[20] A. Kaczor, I.D. Reva, L.M. Proniewicz, R. Fausto, J. Phys. Chem. A 110 (2006) 2360. 